\title{
Disability, Caste, and Intersectionality: Does Co-Existence of Disability and Caste Compound Marginalization for Women Seeking Maternal Healthcare in Southern Nepal?
}

\author{
Hridaya Raj Devkota ${ }^{1, *(\mathbb{C}}$, Andrew Clarke ${ }^{2,3}{ }^{\complement}$, Emily Murray ${ }^{1}$, Maria Kett ${ }^{4}\left(\mathbb{C}\right.$ and Nora Groce ${ }^{4}(\mathbb{C}$ \\ 1 Department of Epidemiology and Public Health, University College London (UCL), 1-19 Torrington Place, \\ London WC1E 6BT, UK; emily.murray@ucl.ac.uk \\ 2 Global Programmes, Save the Children UK, 1 St. John's Lane, London EC1M 4AR, UK; \\ andrewcws@gmail.com \\ 3 Division of Health Research, Lancaster University, Lancaster LA1 4AT, UK \\ 4 The International Disability Research Centre, Department of Epidemiology and Health Care, University \\ College London (UCL), 1-19 Torrington Place, London WC1E 6BT, UK; m.kett@ucl.ac.uk (M.K.); \\ nora.groce@ucl.ac.uk (N.G.) \\ * Correspondence: hridayadevkota@hotmail.com
}

Citation: Devkota, H.R.; Clarke, A.; Murray, E.; Kett, M.; Groce, N. Disability, Caste, and Intersectionality: Does Co-Existence of Disability and Caste Compound Marginalization for Women Seeking Maternal Healthcare in Southern Nepal?. Disabilities 2021, 1, 218-232. https://doi.org/10.3390/disabilities 1030017

Academic Editors: Michelle A. Meade and Nathan Wilson

Received: 30 May 2021

Accepted: 12 August 2021

Published: 18 August 2021

Publisher's Note: MDPI stays neutral with regard to jurisdictional claims in published maps and institutional affiliations.

Copyright: (c) 2021 by the authors. Licensee MDPI, Basel, Switzerland. This article is an open access article distributed under the terms and conditions of the Creative Commons Attribution (CC BY) license (https:// creativecommons.org/licenses/by/ $4.0 /)$.
Abstract: Background: Disability and caste are two different forms of oppression; however, people of the Dalit caste in Nepal and people with disabilities commonly face similar types of marginalities. Dalit women with disabilities may experience double discrimination because of the intersectionality of disability and caste. This study examines whether the disability and caste identity of women together affects and compounds the utilization of maternal healthcare services. Methods: A crosssectional survey was conducted using a semi-structured questionnaire among a total of 354 Dalit and non-Dalit women, with and without a disability aged between 15-49 years. Maternal healthcare service utilization was assessed by antenatal care (ANC), health facility (HF) delivery, and postnatal care (PNC) during the last pregnancy. Logistic regression was performed to detect the predictors of service utilization and identify whether disability and caste were associated with service utilization. First, disability and caste were fitted separately in models. Secondly, the intersectionality of disability and caste was tested by inclusion of a disability ${ }^{*}$ caste interaction term. Finally, the confounding effect of socio-demographic factors was investigated. Results: Out of surveyed women, $73 \%$ had $4+$ ANC visits, $65 \%$ had HF delivery, and $29 \%$ had a PNC visit during their last pregnancy. Women with a disability had lower odds of HF delivery (OR 0.50, CI 0.30-0.84) and PNC (OR 0.47, CI 0.25-0.88) than women without a disability. Adjustment for women's age and household wealth explained associations in HF delivery by women with disabilities. There was no association between caste and service utilization. Disability overrode caste, and there was no other evidence of effect modification by women's caste status in the utilization. However, a weak interaction effect in the utilization of ANC services was found in the caste group by their education (OR 0.19, 95\% CI 0.05-0.74). Conclusions: Disabled women-whether Dalit or non-Dalit—had lower rates of utilizing all maternal healthcare services than non-disabled women. Interestingly, Dalit women with disabilities were more likely to receive PNC than non-Dalit women with disabilities. Increasing equity in maternal healthcare service utilization requires that traditional approaches to service development and program intervention be re-examined and more nuanced interventions considered to ensure improved access and outcomes among all vulnerable groups.

Keywords: disability; caste; intersectionality; maternal health; healthcare service utilization; Nepal

\section{Background}

Despite good progress in the past two decades, maternal mortality in Nepal remains high at 238 per 100,000 live births [1]. Disparities in health and healthcare access, delays 
in seeking and obtaining care, and poor quality of care due to lack of skilled health professionals are key contributing factors to maternal deaths [2,3]. Studies also show significant differences in the utilization of maternal healthcare services and health outcomes among social groups $[4,5]$.

Out of 125 ethnic and caste groups in Nepal, the 2010 census listed 28 social groups as Dalits ('untouchables'), comprising $13.6 \%$ of the population [6,7]. 'Dalits' are at the bottom of the caste hierarchy, and the word literally means "oppressed". The caste system and the discrimination linked to this manifest as a rigid form of exploitation and oppression in South Asia that has left some groups, such as the Dalits, marginalized and vulnerable [8]. The caste system is a complex culturally constructed social structure that provides a hierarchy of social roles inherited by birth with limited social mobility, which has historically resulted in restricted education, occupational, and other opportunities for groups regarded to be lower caste (Dalits) throughout their life course. Caste is repressive and discriminatory in nature, in contrast to culture, which might be regarded as a more cohesive phenomenon. In the context of this study, socially marginalized populations, such as disabled and disadvantaged caste groups (Dalit women), are less likely to utilize maternal healthcare services [5,9-11].

\subsection{Disability and Maternal Healthcare Service Utilization}

The UN Convention on the Rights of Persons with Disabilities (2006) defines disability as '.. those who have long-term physical, mental, intellectual or sensory impairments which in interaction with various barriers may hinder their full and effective participation in society on an equal basis with others' [12]. About 15\% of the world's population is estimated to have some form of disability, with a higher prevalence among women [13]. Reported rates of disability in Nepal vary widely. The Nepal census 2011 found less than $2 \%$ of the population with disabilities [6], whereas other surveys have reported prevalence rates ranging from 1 to $13 \%$ [14] and up to $29 \%$ for women with children [9,15].

Around the world, women with disabilities face numerous barriers in accessing maternal healthcare services [16-18]. Findings in Nepal are similar to those found in other low and middle-income countries $[19,20]$. Poor quality of care and negative health worker attitudes, physical barriers, cost and lack of family support, and poverty all are barriers faced by women with disabilities when accessing maternal healthcare services $[9,21,22]$.

\subsection{Caste and Maternal Healthcare Service Utilization}

The literature demonstrates that caste has a strong influence on maternal healthcare service utilization, including the quality of care [23-25]. Dalit women endure worse health than their upper caste counterparts across almost all indicators in Nepal [26]. However, one study showed no effect of caste in the use of healthcare services [27]. The contradictory findings suggest a more complex picture and suggest that whilst caste is a factor, caste alone may not be the sole determinant in women's health indicators and in accessing healthcare services. Few papers make a direct reference to the combined issues of disability and caste. Based on the literature it can be hypothesized that the co-existence of gender discrimination together with caste and disability could have a compounding negative impact on disabled and Dalit women's maternal healthcare experiences.

\subsection{Intersectionality between Disability and Caste}

Intersectionality is broadly understood here as the intersection between disability and caste identity, influencing individual lives, social practices, institutional arrangements, and cultural ideologies with power outcomes [28] that ultimately impact service use by these population groups. The interactions that take place between and within multiple dimensions and power structures, and social systems, lead to various forms of oppressive experiences.

Little is known about the combined effect of disability and caste in the context of maternal health. In this study, we set out to understand whether the combined effect of 
disability and caste would further compound marginalization and impact access to care by disabled women and their newborns.

This study hypothesized that healthcare services may be least accessible to disabled, disadvantaged 'Dalit women'. It also theorized that higher-caste non-disabled and disabled women have greater access to healthcare services because of their higher status in society, higher level of education, better economic status, and greater participation in and access to community resources. Further, while higher-caste disabled women's access to healthcare might be lower than that of their non-disabled peers, it was anticipated that this would still be better than that of either Dalit women or disabled Dalit women. This has implications for women in Nepal, where different forms of social oppression such as gender inequality, disability, and caste persist, despite measures to address them [29,30]. No studies to date have explored the intersection of caste and disability in the context of maternal healthcare service access and utilization in Nepal. To better understand the complex relationship between disability and caste in the utilization of maternal healthcare services, the study aims to identify the key predictors of maternal healthcare services by women with disabilities and examine whether the disability and caste identity of women affects and compounds the utilization of maternal healthcare services.

Nepal has adopted the United Nations Sustainable Development Goals (SDGs), and aspires to ensure health and wellbeing for all (SDG 3), requiring a commitment to the reduction of disparities in healthcare access, in particular for poor and marginalized communities. In speaking to that agenda, it is hoped that this study makes a contribution to the design of more equitable health policies by better informing decision-makers.

\section{Method}

\subsection{Setting}

The study was conducted in Rupandehi, a southern district of Nepal with a population of 880,196 of which $50.89 \%$ are women [6]. Just over $25 \%$ of the population are Janajati (indigenous), followed by $21 \%$ from high or advantaged Brahmin and Chhetrie caste groups, and $12 \%$ from the more disadvantaged Dalit caste groups. Only $1.12 \%$ of the district population are reported to have a disability [6].

Primary healthcare services including maternal care in the district are delivered through five primary healthcare centers (PHCC), six urban health clinics (UHC), six health posts (HP) and 58 sub-health posts (SHP). One district hospital and one zonal hospital (covering six districts) provide secondary care services. In addition to the government health services, there is a wide network of NGOs and private sector services providing private hospitals, nursing homes, clinics, and pharmacies/drug shops [31].

\subsection{Study Design}

A cross-sectional survey was conducted among married and unmarried women aged between 15-49 years, who had been pregnant within the last five years. Women with two or more pregnancies or deliveries were instructed to refer to their most recent pregnancy or childbirth. The sample was drawn from four different categories: Dalit and non-Dalit women with a disability, Dalit women without a disability, and non-Dalit women without a disability. While disabled and Dalit women were of particular interest in the study, nonDalit non-disabled women were included for comparison. Women with a severe intellectual disability; those unable to provide responses; and those with a hearing impairment with whom it was not possible to communicate by verbal and or non-verbal means, such as Nepali Sign Language, were excluded from the study.

\subsection{Sample}

The study used a non-probability, multi-stage sampling method for selection and recruitment of participants. In the first stage, disabled women within the criteria were identified using the most recent census and with the help of local organizations of disabled people (ODPs). Out of 119 disabled women identified through census, $79(66.4 \%)$ women 
were interviewed but 30 could not be located, four did not meet the disability criteria of the UN Washington Group questionnaire (www.washingtongroup-disability.com, accessed on 13 October 2014), and six could not be interviewed due to communication difficulties. Based on the number of disabled women, the number of non-disabled Dalit and non-disabled non-Dalit women for interview was determined using a 1:2:2 ratios resulting in a total sample size of 354 for study.

\subsection{The Tool and Data Collection}

A semi-structured questionnaire with 95 questions covering demographics, maternal healthcare, and service utilization was adapted from previously developed standard questions used in Nepal (such as the NDHS questionnaire), with additional new questions relating to disability and empowerment. The questionnaire was field-tested, refined, and validated before use in the interviews [32]. Twelve trained woman field researchers with public health background having experience and skills in research data collection collected the data. The data was checked to ensure completeness of information; for any found incomplete, participants were revisited to complete and confirm the missing information.

\section{Measures}

\subsection{Outcome Measures}

Three measures of maternal healthcare service utilization were used: antenatal care (ANC), delivery, and postnatal care (PNC). The study considered four or more ANC visits during the last pregnancy as adequate minimum utilization [33]. Utilization for delivery was assessed as delivery in any type of officially recognized health facility-private or public birthing centers, health posts, primary healthcare centers, or hospitals. Adequate postnatal care utilization was determined as 'at least one distinct visit to a health facility for post-natal care' made within one week of delivery. Table 1 shows the outcome measure variables, exposures, and covariates used in the study.

Table 1. Variables and their description measuring maternal healthcare service utilization.

\begin{tabular}{|c|c|c|}
\hline Measure & Definition/Coding & Level of Measurement \\
\hline \multicolumn{3}{|l|}{ Outcome Variables } \\
\hline ANC Visit & $\begin{array}{l}\text { Attendance at a health facility (HF) by a pregnant woman for antenatal care } \\
\text { during last pregnancy ( } 0=<4 \text { visit, } 1=4+\text { visit })\end{array}$ & Binary \\
\hline HF Delivery & $\begin{array}{l}\text { Most recent childbirth at a health facility (HF) designated for safe delivery } \\
(0=\text { Home delivery, } 1=\text { HF delivery })\end{array}$ & Binary \\
\hline PNC Visit & $\begin{array}{l}\text { Attendance at a HF for postnatal care by a woman within } 7 \text { days of last } \\
\text { childbirth }(0=\mathrm{No}, 1=\text { Yes })\end{array}$ & Binary \\
\hline \multicolumn{3}{|l|}{ Exposure Variables } \\
\hline Disability & $\begin{array}{l}\text { Disability status of respondent women meeting Washington Group } \\
\text { Questionnaire criteria }(1=\text { Non-disabled, } 2=\text { disabled })\end{array}$ & Binary \\
\hline Caste & Self-reported caste of respondent woman ( 1 = Dalit, 2 = Non-Dalit) & Binary \\
\hline \multicolumn{3}{|l|}{ Covariates } \\
\hline Place of residence & $\begin{array}{l}\text { At the time of survey, respondent living in VDC are considered rural and those } \\
\text { living in municipality are urban }(1=\text { rural, } 2=\text { urban })\end{array}$ & Binary \\
\hline Age & $\begin{array}{l}\text { Completed age of women at the time of survey in years } \\
(1=15-24,2=25-34,3=35-49)\end{array}$ & Categorical \\
\hline Parity & $\begin{array}{l}\text { Number of pregnancy or childbirths in lifetime } \\
(1=\text { primipara, } 2=\text { multipara })\end{array}$ & Binary \\
\hline Respondent's education & $\begin{array}{l}\text { Number of years of school education completed by the women }(1=\text { illiterate, } 2= \\
\text { literate/primary education up to class } 5,3=\text { secondary education or above })\end{array}$ & Categorical \\
\hline $\begin{array}{l}\text { Knowledge and awareness } \\
\text { Index }\end{array}$ & $\begin{array}{l}\text { Knowledge of danger signs spontaneously cited relating to pregnancy, } \\
\text { childbirth and postpartum (An additive index })(0=\text { no knowledge at all, } 1= \\
\text { little knowledge or low level of awareness, } \\
2 \text { = Enough knowledge-high level of awareness) }\end{array}$ & Ordinal \\
\hline
\end{tabular}


Table 1. Cont.

\begin{tabular}{cl}
\hline \multicolumn{1}{c}{ Measure } & \multicolumn{1}{c}{ Definition/Coding } \\
\hline Empowerment Index & $\begin{array}{l}\text { An index developed using } 24 \text { questionnaire items at individual, family, and } \\
\text { community level indicators }(1=\text { low, } 2=\text { medium, and } 3=\text { high })\end{array}$ \\
\hline Household Wealth Index & $\begin{array}{l}\text { Wealth index developed based on socio-economic indicators and household } \\
\text { assets reported at the time of survey }(1=\text { low, } 2=\text { middle, and } 3=\text { high })\end{array}$ \\
\hline
\end{tabular}

\subsection{Household Wealth Index}

The household wealth index variable was constructed using 22 indicators of household possessions, resulting in a total score of 26 . Household possession or dwelling characteristics were chosen from the Nepal Demographic Health Survey 2011. Except for roofing materials and source of water, all variables were dichotomized assigning the code 0 or 1 . Roofing materials was assigned the weight 1 with natural/non-durable roofing materials; 2 with durable roofing materials; and 3 for long, durable roofing such as cement and concrete. Households using surface water/shallow wells were given the score 1, those using tube wells were assigned 2 , and those using piped water were given 3 . Women were ranked according to the score of their households. For the purpose of analysis, the lowest two and the highest two groups were collapsed to make three categories (low, medium and high) of wealth ranking.

\subsection{Women's Empowerment Index}

Four dimensions: economic, socio-cultural, familial/interpersonal, and political, were used to construct the women's empowerment index [34,35]. These dimensions were adapted to reflect the local context at individual/family (micro) and community (meso) level indicators, with 24 questionnaire items required to derive a score. All questionnaire items were equally weighted, and dichotomized, and a composite measure was created using the sum (maximum score of 24).

\subsection{Knowledge and Awareness Index}

The knowledge and awareness index was created by asking two questions. Firstly, respondents were asked: 'Are you aware of any problems that are potentially dangerous to the mother during pregnancy and childbirth?' Those who answered affirmatively were asked the second question: 'What are the danger signs to mothers during pregnancy, childbirth and after delivery?' Women who answered 'No' for the first question were given a score of 0 , and women stating one to three correct danger signs to the second question were given a score of 1 . Those stating four or more signs scored 2.

\subsection{Statistical Analysis}

Data was entered using EPI-Info version 3.4.1 and then transferred into SPSS (version 16.0 for Windows) for analysis. The associations between the measures of utilization-ante-natal care (any check-up and frequency of check-up), delivery (HF vs. home delivery), post-natal check-up (yes/no), and disability/Dalit status-were examined using cross tabulations and chi-square tests. Logistic regression analysis was carried out to test whether disability or Dalit status was related to utilization measures once socio-demographic, empowerment, and awareness characteristics of individuals had been taken into account. Confounding was investigated by multivariate analysis. Further, disability and caste were fitted separately in models and intersectionality of disability and caste was tested by inclusion of a disability*aste interaction term.

\section{Results}

\subsection{Socio-Demographic Characteristics of Survey Participants}

Table 2 shows the characteristics of survey participants. Of 354 women surveyed, $40 \%$ were non-disabled non-Dalits, about $38 \%$ were non-disabled Dalits, $17 \%$ disabled 
non-Dalits, and 5\% were disabled-Dalits. Over $80 \%$ participants lived in rural areas. Approximately half of the respondents were 25-34 years, 38\% were 15-24 years, and the remaining were between 35-49 years of age. Nearly one-third of women reported having no education or were illiterate, and one fifth had no knowledge at all about danger signs in pregnancy. The majority of participants (56\%) were primiparous. Over $19 \%$ participants were assessed as having higher levels of empowerment and autonomy- $58.8 \%$ with medium levels and $21.8 \%$ with low levels. Similarly, one fifth of women were ranked as having higher levels of household wealth, $56.5 \%$ with middle levels, and $22.9 \%$ with lower levels.

Table 2. Characteristics of study participants.

\begin{tabular}{|c|c|}
\hline Background Characteristics & $n=354(\%)$ \\
\hline \multicolumn{2}{|l|}{ Participant Type } \\
\hline Non-disabled non-Dalit & $142(40.1 \%)$ \\
\hline Non-disabled Dalit & $133(37.6 \%)$ \\
\hline Disabled non-Dalit & $61(17.2 \%)$ \\
\hline Disabled Dalit & $18(5.1 \%)$ \\
\hline \multicolumn{2}{|l|}{ Place of Residence } \\
\hline Rural & $284(80.2 \%)$ \\
\hline Urban & $70(19.8 \%)$ \\
\hline \multicolumn{2}{|l|}{ Respondent's Age } \\
\hline $15-24$ Years & $134(37.9 \%)$ \\
\hline 25-34 Years & $172(48.6 \%)$ \\
\hline 35-49 Years & $48(13.6 \%)$ \\
\hline \multicolumn{2}{|l|}{ Education } \\
\hline Illiterate & $116(32.8 \%)$ \\
\hline Literate/primary (up to 5 Class) & $117(33.1 \%)$ \\
\hline Secondary ( 6 class and above) & $121(34.2 \%)$ \\
\hline \multicolumn{2}{|l|}{ Knowledge and Awareness } \\
\hline No knowledge at all & $71(20.1 \%)$ \\
\hline Little knowledge (low level of awareness) & $138(39.0 \%)$ \\
\hline Enough knowledge (high level of awareness) & $145(41.0 \%)$ \\
\hline \multicolumn{2}{|l|}{ Parity } \\
\hline Primipara & $198(55.9 \%)$ \\
\hline Multipara & $156(44.1 \%)$ \\
\hline \multicolumn{2}{|l|}{ Women Empowerment Index } \\
\hline Low & $77(21.8 \%)$ \\
\hline Medium & $208(58.8 \%)$ \\
\hline High & $69(19.5 \%)$ \\
\hline \multicolumn{2}{|l|}{ Household Wealth Index } \\
\hline Low $(<40 \%$ in ranking) & $81(22.9 \%)$ \\
\hline Middle (40-60\% in ranking) & $200(56.5 \%)$ \\
\hline High $(>60 \%$ in ranking) & $73(20.6 \%)$ \\
\hline
\end{tabular}

\subsection{Maternal Health Care Service Utilization}

Over $73 \%$ of women had attended the recommended four or more ANC visits in their last pregnancy. Less than two-thirds of participants reported that they had a health facility (HF) delivery, and only $29 \%$ received postnatal care. Among the four groups, non-disabled non-Dalit women reported the highest percentage of utilization of all services followed by non-disabled Dalits. Disabled Dalits used ANC and HF delivery the least. However, the percentage of disabled Dalits using postnatal care services was higher than disabled non-Dalit women ( $28 \%$ vs. $18 \%$ ). (Table 3 ). 
Table 3. Maternal health care service utilization by different groups of study participants.

\begin{tabular}{|c|c|c|c|c|c|c|}
\hline Outcome Variables & $\begin{array}{l}\text { Disabled } \\
\text { Dalit }\end{array}$ & $\begin{array}{c}\text { Disabled } \\
\text { Non-Dalit }\end{array}$ & $\begin{array}{l}\text { Non-Disabled } \\
\text { Dalit }\end{array}$ & $\begin{array}{c}\text { Non-Disabled } \\
\text { Non-Dalit }\end{array}$ & Total & $p$-Value \\
\hline & $n=18$ & $n=51$ & $n=133$ & $n=142$ & $n=354$ & \\
\hline Utilization of $4+$ ANC & $10(56 \%)$ & $37(73 \%)$ & $101(76 \%)$ & $111(78 \%)$ & $259(73 \%)$ & 0.136 \\
\hline Health Facility Delivery & $9(50 \%)$ & $31(61 \%)$ & $84(63 \%)$ & $105(74 \%)$ & $229(65 \%)$ & 0.008 \\
\hline Utilization of PNC services & $5(28 \%)$ & $9(18 \%)$ & $40(30 \%)$ & $49(35 \%)$ & $103(29 \%)$ & 0.017 \\
\hline
\end{tabular}

Pearson Chi-square test of significance.

\subsection{Bivariate Analysis Result}

Table 4 illustrates that there was no significant relationship between an individual's disability and caste status and attendance for the full-recommended number of antenatal care visits $(p>0.5)$. However, education, empowerment, and household wealth factors showed some relationship with four or more ANC visits $(p<0.05)$. Compared to illiterate women, there was higher odds of four or more ANC visits with increasing levels of women's education (OR 2.27, 95\% CI 1.22-4.23 for literate or primary level education; OR 3.61, 95\% CI 1.84-7.08 for secondary or above education). It was also evident that women with greater levels of empowerment/autonomy had higher odds of using ANC services (OR 1.91, 95\% CI 1.05-3.49 for medium, and OR 4.40, 95\% CI 1.74-11.10 for high level empowerment). Additionally, women with higher household wealth index (OR 1.98, 95\% CI 1.05-3.72) were more likely to receive the full 4 ANC services than those from households with a low index.

Table 4. Bivariate analysis.

\begin{tabular}{|c|c|c|c|c|c|c|c|c|c|}
\hline \multirow{2}{*}{ Variables } & \multicolumn{3}{|c|}{ ANC (4+) } & \multicolumn{3}{|c|}{ HF Delivery } & \multicolumn{3}{|c|}{ PNC (At Least 1) } \\
\hline & OR & $95 \% \mathrm{CI}$ & $p$-Value & OR & $95 \%$ CI & $p$-Value & OR & $95 \%$ CI & $p$-Value \\
\hline \multicolumn{10}{|l|}{ Disability } \\
\hline Non-disabled & 1 & & & 1 & & & 1 & & \\
\hline Disabled & 0.63 & $(0.34-1.16)$ & 0.138 & 0.50 & $(0.30-0.84)$ & 0.009 & 0.47 & $(0.25-0.88)$ & 0.019 \\
\hline \multicolumn{10}{|l|}{ Caste } \\
\hline Non-Dalit & 1 & & & 1 & & & 1 & & \\
\hline Dalit & 0.81 & $(0.48-1.37)$ & 0.440 & 0.77 & $(0.49-1.20)$ & 0.243 & 0.93 & $(0.60-1.52)$ & 0.839 \\
\hline \multicolumn{10}{|l|}{ Place of Residence } \\
\hline Rural & 1 & & & 1 & & & 1 & & \\
\hline Urban & 1.92 & $(0.90-4.09)$ & 0.093 & 2.02 & $(1.10-3.72)$ & 0.023 & 0.54 & $(0.28-1.01)$ & 0.056 \\
\hline \multicolumn{10}{|l|}{ Age } \\
\hline 15-24 years & 1 & & & 1 & & & 1 & & \\
\hline $25-34$ years & 0.64 & $(0.36-1.14)$ & 0.127 & 0.42 & $(0.25-0.71)$ & 0.001 & 1.03 & $(0.63-1.69)$ & 0.896 \\
\hline $35-49$ years & 0.48 & $(0.21-1.12)$ & 0.088 & 0.21 & $(0.10-0.42)$ & 0.000 & 0.44 & $(0.19-1.03)$ & 0.059 \\
\hline \multicolumn{10}{|l|}{ Education } \\
\hline Illiterate & 1 & & & 1 & & & 1 & & \\
\hline Primary Education & 2.27 & $(1.22-4.23)$ & 0.010 & 2.27 & $(1.34-3.84)$ & 0.002 & 1.54 & $(0.86-2.77)$ & 0.150 \\
\hline Secondary or higher & 3.61 & $(1.84-7.08)$ & 0.000 & 14.63 & $(6.94-30.83)$ & 0.000 & 1.87 & $(1.05-3.33)$ & 0.034 \\
\hline \multicolumn{10}{|l|}{ Parity } \\
\hline Primi & 1 & & & 1 & & & 1 & & \\
\hline Multi & 0.60 & $(0.35-1.01)$ & 0.054 & 0.23 & $(0.14-0.36)$ & 0.000 & 0.54 & $(0.33-0.86)$ & 0.011 \\
\hline \multicolumn{10}{|l|}{$\begin{array}{l}\text { Knowledge \& } \\
\text { awareness }\end{array}$} \\
\hline No knowledge & 1 & & & 1 & & & 1 & & \\
\hline Little & 1.07 & $(0.53-2.14)$ & 0.859 & 1.04 & $(0.58-1.87)$ & 0.891 & 0.87 & $(0.45-1.65)$ & 0.663 \\
\hline Enough & 1.51 & $(0.74-3.06)$ & 0.258 & 2.05 & $(1.12-3.75)$ & 0.020 & 1.25 & $(0.67-2.33)$ & 0.483 \\
\hline \multicolumn{10}{|l|}{ Empowerment } \\
\hline Low & 1 & & & 1 & & & 1 & & \\
\hline Medium & 1.91 & $(1.05-3.49)$ & 0.034 & 1.04 & $(0.60-1.80)$ & 0.887 & 1.01 & $(0.56-1.82)$ & 0.980 \\
\hline High & 4.40 & $(1.74-11.10)$ & 0.002 & 1.69 & $(0.83-3.44)$ & 0.150 & 1.37 & $(0.68-2.78)$ & 0.381 \\
\hline \multicolumn{10}{|l|}{ Household Wealth } \\
\hline Low & 1 & & & 1 & & & 1 & & \\
\hline Middle & 1.98 & $(1.05-3.72)$ & 0.034 & 2.76 & $(1.62-4.70)$ & 0.000 & 1.50 & $(0.82-2.75)$ & 0.191 \\
\hline High & 1.63 & $(0.76-3.47)$ & 0.208 & 5.84 & $(2.77-12.30)$ & 0.000 & 1.83 & $(0.90-3.74)$ & 0.097 \\
\hline
\end{tabular}


The respondents' disability status showed significant associations with health facility delivery $(p<0.05)$, whereas the respondent's caste did not show any association $(p>0.05)$. The odds of health facility delivery for disabled non-Dalit and disabled Dalits women was 60\% (OR 0.40, 95\% CI 0.21-0.77) and 65\% (OR 0.35, 95\% CI 0.13-0.96) lower, respectively, than non-disabled non-Dalits. Urban women were also twice as likely to have a HF delivery compared to rural women (OR 2.02, 95\% CI 1.10-3.72).

Women's education, age, and parity were strong factors influencing whether to deliver at home or HF. Women with secondary level or higher education had greater odds than those who were illiterate or had no education (OR 14.63, 95\% CI 6.94-30.83). The odds ratio of HF delivery for the women age between 25-34 years was 0.42 , 95\% CI 0.25-0.71; and 35-49 years had OR 0.21, 95\% CI 0.10-0.42. Multiparous women had lower odds (OR 0.23, 95\% CI 0.14-0.36) than primiparous. Women's knowledge and awareness of pregnancy danger signs and household wealth were also found to be strong predictors for giving birth at a health facility (OR 2.05, 95\% CI 1.12-3.75 for adequate knowledge and awareness and OR 5.84, 95\% CI 2.77-12.30 for highest wealth ranking groups). (Table 4).

Women's disability and some socio-demographic factors such as respondent's education, age at marriage, and parity were associated with PNC service utilization $(p<0.05)$. Women with secondary or higher education had greater odds (OR 1.87, 95\% CI1.05-3.33) of utilizing PNC services than those with no education. Women with two or more pregnancies were $50 \%$ less likely to use PNC than those with their first pregnancy (OR 0.54, 95\% CI 0.33-0.86). No relationship was found between the respondent's caste and PNC service utilization $(p>0.05)$ (Table 4$)$.

\subsection{Multi-Variate Analysis}

Table 5 shows odds ratios for disability status with all three service utilization outcomes, adjusted for socio-demographic and household factors theorized to be a potential confounders of associations. Overall, disabled respondents reported less odds of utilization in all three outcomes, compared to non-disabled. In the unadjusted model, there was no association between disability and the four recommended ANC visits. After adjusting for potential confounding variables, the data did not show a significant relationship between disability and ANC visits.

Disabled women had lower odds of HF delivery (OR 0.48, 95\% CI 0.26-0.86) and PNC (OR 0.47, 95\% CI 0.25-0.88) compared to non-disabled women. However, after adjustment for women's age, there was no association between disability and HF delivery. Adjustment for place of residence (location) and parity reduced the association. In the full model, there was not a significant association between disability and HF delivery. The same group of confounders affected the relationship between disability and PNC in the same way as in HF delivery.

Tables 6 and 7 show the models with interaction terms that look at the effect of interactions between exposures and key predictors of service utilization, including age, education, parity, and wealth factors, and their association in utilization for disabled and non-disabled, and Dalit and non-Dalit, women. Given the data, in most cases there was insufficient evidence of interaction effect between disability and women's age, education, parity, and household wealth at 5\% significant level (Table 6). However, a weak interaction effect in the utilization of recommended ANC services found in the caste group by their education (OR 0.19, 95\% CI 0.05-0.74). (Table 7). 
Table 5. Unadjusted and adjusted odds ratio of disability with maternal health care utilization.

\begin{tabular}{|c|c|c|c|c|c|c|}
\hline \multirow{2}{*}{ Factors } & \multicolumn{2}{|c|}{ ANC 4+ Visit } & \multicolumn{2}{|c|}{ HF Delivery } & \multicolumn{2}{|c|}{ PNC Visit } \\
\hline & OR & $95 \% \mathrm{CI}$ & OR & $95 \% \mathrm{CI}$ & OR & $95 \% \mathrm{CI}$ \\
\hline Disability Only & 0.63 & $0.34-1.16$ & $* 0.48$ & $0.26-0.86$ & $* 0.47$ & $0.25-0.88$ \\
\hline Disability + Caste & 0.58 & $0.31-1.09$ & $* * 0.45$ & $0.26-0.77$ & $* 0.46$ & $0.24-0.88$ \\
\hline Non-Dalit & 1 & & 1 & & 1 & \\
\hline Dalit & 0.74 & $0.43-1.27$ & 0.66 & $0.41-1.05$ & 0.93 & $0.58-1.50$ \\
\hline Disability + Education & 0.68 & $0.36-1.28$ & $* 0.54$ & $0.32-0.91$ & $* 0.46$ & $0.26-0.92$ \\
\hline Illiterate/no education & 1 & & 1 & & 1 & \\
\hline Primary education & $* 2.18$ & $1.17-4.08$ & $* * 2.12$ & $1.25-3.61$ & 1.44 & $0.79-2.60$ \\
\hline Secondary or higher & $* * * 3.55$ & $1.81-6.98$ & $* * * 14.73$ & $6.94-31.26$ & $* 1.81$ & $1.01-3.24$ \\
\hline Disability + Location & & & $* 0.54$ & $0.32-0.91$ & & \\
\hline Rural & & & 1 & & & \\
\hline Urban & & & $* 1.85$ & $1.01-3.43$ & & \\
\hline Disability + Women's Age & & & 0.72 & $0.41-1.26$ & & \\
\hline $15-24$ yrs & & & 1 & & & \\
\hline $25-34$ yrs & & & $* * 0.44$ & $0.26-0.74$ & & \\
\hline $35-49$ yrs & & & $* * * 0.25$ & $0.12-0.52$ & & \\
\hline Disability + Parity & & & $* 0.61$ & $0.35-1.06$ & $* 0.52$ & $0.27-0.98$ \\
\hline Primi & & & 1 & & 1 & \\
\hline Multi & & & $* * * 0.24$ & $0.15-0.39$ & $* 0.58$ & $0.35-0.93$ \\
\hline $\begin{array}{l}\text { Disability }+ \\
\text { Knowledge/Awareness }\end{array}$ & & & $* 0.54$ & $0.32-0.91$ & & \\
\hline No knowledge & & & 1 & & & \\
\hline Little & & & 1.00 & $0.55-1.81$ & & \\
\hline Enough & & & $* 1.89$ & $1.02-3.48$ & & \\
\hline Disability + Empowerment & 0.64 & $0.34-1.19$ & & & & \\
\hline Low & 1 & & & & & \\
\hline Medium & * 1.91 & $1.05-3.49$ & & & & \\
\hline High & $* * 4.37$ & $1.23-11.05$ & & & & \\
\hline Disability + Wealth Index & 0.70 & $0.37-1.31$ & 0.68 & $0.39-1.19$ & & \\
\hline Low & 1 & & 1 & & & \\
\hline Middle & 1.85 & $0.98-3.52$ & $* * 2.54$ & $1.47-4.39$ & & \\
\hline High & 1.48 & $0.68-3.23$ & $* * * 5.21$ & $2.43-11.17$ & & \\
\hline Full Model & 0.71 & $0.37-1.38$ & 0.76 & $0.38-1.50$ & $* 0.52$ & $0.27-0.99$ \\
\hline
\end{tabular}

${ }^{*} p<0.05,{ }^{* *} p<0.01$, and ${ }^{* * *} p<0.001$

Table 6. Models with interaction terms analyzing the effects of interactions between key predictors and service utilization by disability.

\begin{tabular}{|c|c|c|c|c|c|c|c|c|c|}
\hline \multirow{2}{*}{ Predictors } & \multicolumn{3}{|c|}{ ANC4+ } & \multicolumn{3}{|c|}{ HF Delivery } & \multicolumn{3}{|c|}{ PNC } \\
\hline & OR & $95 \%$ CI & $p$ Value & OR & $95 \%$ CI & $p$ Value & OR & $95 \% \mathrm{CI}$ & $p$ Value \\
\hline $\begin{array}{l}\text { Disability + Age } \\
\text { Disabled } \\
\text { Non-disabled }\end{array}$ & 0.83 & $0.20-3.43$ & 0.800 & 0.65 & $0.20-2.06$ & 0.462 & 1.23 & $0.26-5.88$ & 0.794 \\
\hline $\begin{array}{l}\text { Age } \\
15-24 \text { years } \\
25-34 \text { years } \\
35-49 \text { years }\end{array}$ & $\begin{array}{l}2.02 \\
1.27\end{array}$ & $\begin{array}{l}0.65-6.34 \\
0.42-3.85\end{array}$ & $\begin{array}{l}0.226 \\
0.674\end{array}$ & $\begin{array}{l}4.41 \\
1.55\end{array}$ & $\begin{array}{c}1.64-11.88 \\
0.60-3.97\end{array}$ & $\begin{array}{l}0.003 \\
0.364\end{array}$ & $\begin{array}{l}2.98 \\
2.83\end{array}$ & $\begin{array}{l}0.83-10.76 \\
0.79-10.18\end{array}$ & $\begin{array}{l}0.096 \\
0.110\end{array}$ \\
\hline $\begin{array}{l}\text { Disabled } \\
15-24 \text { years } \\
25-34 \text { years } \\
35-49 \text { years }\end{array}$ & $\begin{array}{l}0.61 \\
0.95\end{array}$ & $\begin{array}{l}0.08-4.50 \\
0.18-4.89\end{array}$ & $\begin{array}{l}0.626 \\
0.947\end{array}$ & $\begin{array}{l}0.41 \\
1.69\end{array}$ & $\begin{array}{l}0.08-2.15 \\
0.42-6.79\end{array}$ & $\begin{array}{l}0.290 \\
0.459\end{array}$ & $\begin{array}{c}0 \\
0.56\end{array}$ & $\begin{array}{c}0 \\
0.10-3.31\end{array}$ & $\begin{array}{l}0.999 \\
0.524\end{array}$ \\
\hline $\begin{array}{l}\text { Disability + } \\
\text { Education } \\
\text { Disabled } \\
\text { Non-disabled }\end{array}$ & 0.71 & $0.29-1.76$ & 0.462 & 0.63 & $0.27-1.48$ & 0.292 & 0.27 & $0.08-0.99$ & 0.048 \\
\hline $\begin{array}{l}\text { Education } \\
\text { Illiterate } \\
\text { Primary education } \\
\text { Secondary and above }\end{array}$ & $\begin{array}{l}1.94 \\
4.58\end{array}$ & $\begin{array}{c}0.97-3.85 \\
1.99-10.53\end{array}$ & $\begin{array}{l}0.060 \\
0.000\end{array}$ & $\begin{array}{c}2.28 \\
21.06\end{array}$ & $\begin{array}{c}1.25-4.14 \\
7.76-57.17\end{array}$ & $\begin{array}{l}0.007 \\
0.000\end{array}$ & $\begin{array}{l}1.29 \\
1.56\end{array}$ & $\begin{array}{l}0.68-2.44 \\
0.82-2.95\end{array}$ & $\begin{array}{l}0.440 \\
0.176\end{array}$ \\
\hline
\end{tabular}


Table 6. Cont.

\begin{tabular}{|c|c|c|c|c|c|c|c|c|c|}
\hline \multirow{2}{*}{ Predictors } & \multicolumn{3}{|c|}{ ANC4+ } & \multicolumn{3}{|c|}{ HF Delivery } & \multicolumn{3}{|c|}{ PNC } \\
\hline & OR & $95 \%$ CI & $p$ Value & OR & $95 \%$ CI & $p$ Value & OR & $95 \%$ CI & $p$ Value \\
\hline $\begin{array}{l}\text { Disabled } \\
\text { Illiterate }\end{array}$ & & & & & & & & & \\
\hline Primary education & 2.49 & $0.41-15.11$ & 0.323 & 0.75 & $0.21-2.78$ & 0.671 & 2.01 & $0.35-11.45$ & 0.434 \\
\hline Secondary and above & 0.45 & $0.10-1.84$ & 0.253 & 0.36 & $0.08-1.76$ & 0.208 & 2.42 & $0.48-12.07$ & 0.282 \\
\hline Disability + Parity & & & & & & & & & \\
\hline Disabled & 0.67 & $0.29-1.52$ & 0.334 & 0.58 & $0.28-1.17$ & 0.126 & 0.44 & $0.17-1.13$ & 0.089 \\
\hline $\begin{array}{l}\text { Non-disabled } \\
\text { Parity } \\
\text { Primipara } \\
\text { Multipara } \\
\text { Disabled }\end{array}$ & 1.60 & $0.87-2.91$ & 0.129 & 4.03 & $2.35-6.92$ & 0.000 & 1.65 & $0.97-2.80$ & 0.065 \\
\hline $\begin{array}{l}\text { Primipara } \\
\text { Multipara } \\
\text { Disability + Wealth }\end{array}$ & 1.03 & $0.30-3.60$ & 0.963 & 1.17 & $0.38-3.67$ & 0.783 & 1.37 & $0.38-4.99$ & 0.631 \\
\hline Disabled & 0.82 & $0.15-4.54$ & 0.823 & 1.36 & $0.15-12.36$ & 0.786 & 0.73 & $0.13-4.07$ & 0.720 \\
\hline $\begin{array}{l}\text { Non-disabled } \\
\text { Wealth Index }\end{array}$ & & & & & & & & & \\
\hline Low-wealth group & 0.80 & $0.32-1.97$ & 0.626 & 0.26 & $0.11-0.60$ & 0.002 & 0.70 & $0.31-1.58$ & 0.389 \\
\hline $\begin{array}{l}\text { Middle-wealth group } \\
\text { High-wealth group } \\
\text { Disabled }\end{array}$ & 1.22 & $0.60-2.50$ & 0.584 & 0.49 & $0.24-1.01$ & 0.050 & 0.89 & $0.49-1.63$ & 0.700 \\
\hline Low-wealth group & 0.58 & $0.08-4.36$ & 0.600 & 0.28 & $0.03-3.10$ & 0.301 & 0.64 & $0.08-5.04$ & 0.671 \\
\hline $\begin{array}{l}\text { Middle-wealth group } \\
\text { High-wealth group }\end{array}$ & 1.05 & $0.15-7.33$ & 0.958 & 0.68 & $0.07-7.01$ & 0.743 & 0.68 & $0.10-4.70$ & 0.695 \\
\hline
\end{tabular}

Table 7. Models with interaction terms analyzing the effects of interactions between key predictors and service utilization by caste.

\begin{tabular}{|c|c|c|c|c|c|c|c|c|c|}
\hline \multirow{2}{*}{ Predictors } & \multicolumn{3}{|c|}{ ANC4+ } & \multicolumn{3}{|c|}{ HF Delivery } & \multicolumn{3}{|c|}{ PNC } \\
\hline & OR & $95 \%$ CI & $p$ Value & OR & $95 \%$ CI & $p$ Value & OR & $95 \%$ CI & $p$ Value \\
\hline \multicolumn{10}{|l|}{ Caste + Age } \\
\hline $\begin{array}{l}\text { Dalit } \\
\text { Non-Dalit } \\
\text { Age }\end{array}$ & 3.11 & $0.67-14.44$ & 0.147 & 1.28 & $0.40-4.09$ & 0.683 & 0.32 & $0.07-1.56$ & 0.159 \\
\hline $\begin{array}{l}15-24 \text { years } \\
25-34 \text { years } \\
35-49 \text { years }\end{array}$ & $\begin{array}{l}5.00 \\
2.30\end{array}$ & $\begin{array}{c}1.57-15.94 \\
0.84-6.34\end{array}$ & $\begin{array}{l}0.007 \\
0.106\end{array}$ & $\begin{array}{l}6.10 \\
2.83\end{array}$ & $\begin{array}{c}2.35-15.84 \\
1.22-6.60\end{array}$ & $\begin{array}{l}0.000 \\
0.016\end{array}$ & $\begin{array}{l}1.30 \\
1.17\end{array}$ & $\begin{array}{l}0.41-4.12 \\
0.37-3.67\end{array}$ & $\begin{array}{l}0.653 \\
0.792\end{array}$ \\
\hline $\begin{array}{l}\text { Dalit } \\
\text { 15-24 years } \\
\text { 25-34 years } \\
\text { 35-49 years } \\
\text { Caste + Education }\end{array}$ & $\begin{array}{l}0.15 \\
0.25\end{array}$ & $\begin{array}{l}0.02-0.89 \\
0.05-1.38\end{array}$ & $\begin{array}{l}0.037 \\
0.112\end{array}$ & $\begin{array}{l}0.58 \\
0.44\end{array}$ & $\begin{array}{l}0.14-2.45 \\
0.12-1.66\end{array}$ & $\begin{array}{l}0.460 \\
0.226\end{array}$ & $\begin{array}{l}2.91 \\
3.71\end{array}$ & $\begin{array}{l}0.51-16.53 \\
0.67-20.47\end{array}$ & $\begin{array}{l}0.228 \\
0.132\end{array}$ \\
\hline $\begin{array}{l}\text { Dalit } \\
\text { Non-Dalit } \\
\text { Education } \\
\text { Illiterate }\end{array}$ & 1.79 & $0.79-4.05$ & 0.161 & 1.01 & $0.48-2.11$ & 0.990 & 1.14 & $0.47-2.76$ & 0.769 \\
\hline $\begin{array}{l}\text { Primary education } \\
\text { Secondary and above }\end{array}$ & $\begin{array}{l}3.66 \\
7.27\end{array}$ & $\begin{array}{c}1.45-9.23 \\
2.84-18.62\end{array}$ & $\begin{array}{l}0.006 \\
0.000\end{array}$ & $\begin{array}{c}2.06 \\
20.83\end{array}$ & $\begin{array}{c}0.99-4.28 \\
7.42-58.46\end{array}$ & $\begin{array}{l}0.054 \\
0.000\end{array}$ & $\begin{array}{l}1.91 \\
2.11\end{array}$ & $\begin{array}{l}0.82-4.46 \\
0.81-5.46\end{array}$ & $\begin{array}{l}0.135 \\
0.125\end{array}$ \\
\hline $\begin{array}{l}\text { Dalit } \\
\text { Illiterate } \\
\text { Primary Education } \\
\text { Secondary and above } \\
\text { Caste + Parity }\end{array}$ & $\begin{array}{l}0.38 \\
0.19\end{array}$ & $\begin{array}{l}0.11-1.37 \\
0.05-0.74\end{array}$ & $\begin{array}{l}0.140 \\
0.017\end{array}$ & $\begin{array}{l}1.21 \\
0.41\end{array}$ & $\begin{array}{l}0.42-3.46 \\
0.09-1.83\end{array}$ & $\begin{array}{l}0.727 \\
0.240\end{array}$ & $\begin{array}{l}0.64 \\
0.82\end{array}$ & $\begin{array}{l}0.20-2.10 \\
0.25-2.73\end{array}$ & $\begin{array}{l}0.463 \\
0.745\end{array}$ \\
\hline $\begin{array}{l}\text { Dalit } \\
\text { Non-Dalit } \\
\text { Parity } \\
\text { Primipara } \\
\text { Multipara }\end{array}$ & 1.32 & $0.63-2.78$ & 0.020 & 1.11 & $0.59-2.09$ & 0.736 & 1.01 & $0.48-2.14$ & 0.984 \\
\hline
\end{tabular}


Table 7. Cont.

\begin{tabular}{|c|c|c|c|c|c|c|c|c|c|}
\hline \multirow{2}{*}{ Predictors } & \multicolumn{3}{|c|}{ ANC4+ } & \multicolumn{3}{|c|}{ HF Delivery } & \multicolumn{3}{|c|}{ PNC } \\
\hline & OR & $95 \% \mathrm{CI}$ & $p$ Value & OR & $95 \% \mathrm{CI}$ & $p$ Value & OR & $95 \% \mathrm{CI}$ & $p$ Value \\
\hline $\begin{array}{l}\text { Dalit } \\
\text { Primipara } \\
\text { Multipara } \\
\text { Caste + Wealth }\end{array}$ & 0.46 & $0.16-1.32$ & 0.147 & 0.69 & $0.27-1.79$ & 0.446 & 1.26 & $0.48-3.32$ & 0.638 \\
\hline $\begin{array}{l}\text { Dalit } \\
\text { Non-Dalit } \\
\text { Wealth Index }\end{array}$ & 0.77 & $0.24-2.44$ & 0.656 & 0.76 & $0.22-2.64$ & 0.665 & 1.20 & $0.43-3.33$ & 0.726 \\
\hline $\begin{array}{l}\text { Low-wealth group } \\
\text { Middle-wealth group } \\
\text { High-wealth group }\end{array}$ & $\begin{array}{l}0.73 \\
1.09\end{array}$ & $\begin{array}{l}0.24-2.21 \\
0.47-2.52\end{array}$ & $\begin{array}{l}0.581 \\
0.847\end{array}$ & $\begin{array}{l}0.13 \\
0.48\end{array}$ & $\begin{array}{l}0.05-0.35 \\
0.21-1.14\end{array}$ & $\begin{array}{l}0.000 \\
0.096\end{array}$ & $\begin{array}{l}0.77 \\
0.76\end{array}$ & $\begin{array}{l}0.30-1.98 \\
0.37-1.57\end{array}$ & $\begin{array}{l}0.586 \\
0.462\end{array}$ \\
\hline $\begin{array}{l}\text { Dalit } \\
\text { Low-wealth group } \\
\text { Middle-wealth group } \\
\text { High-wealth group }\end{array}$ & $\begin{array}{l}0.85 \\
1.37\end{array}$ & $\begin{array}{l}0.17-4.11 \\
0.35-5.39\end{array}$ & $\begin{array}{l}0.835 \\
0.652\end{array}$ & $\begin{array}{l}1.89 \\
1.00\end{array}$ & $\begin{array}{l}0.41-8.73 \\
0.25-3.97\end{array}$ & $\begin{array}{l}0.416 \\
0.997\end{array}$ & $\begin{array}{l}0.48 \\
1.13\end{array}$ & $\begin{array}{l}0.11-2.10 \\
0.35-3.73\end{array}$ & $\begin{array}{l}0.330 \\
0.836\end{array}$ \\
\hline
\end{tabular}

\section{Discussion}

This study found that disabled women used all maternal healthcare services less than non-disabled women of all castes. The results suggest that it is the disability status of pregnant Nepali women and not their caste that contributes to the utilization of health facility delivery and postnatal care. Associations between disability and all three maternal healthcare utilization outcomes were entirely explained by the inclusion of education and household wealth, suggesting that the main reasons why disabled women were less likely to utilize maternal healthcare services was due to social and household circumstances.

There are few statistics available to compare the findings of this study within Nepal as the government has limited mechanisms for recording disability data, and most previous studies on maternal healthcare have not included disability. The few qualitative studies conducted in this field in Nepal indicate poor utilization of services by women with disabilities during their pregnancy and childbirth $[9,15]$. This contrasts with findings from high-income countries, where a more structured and intensive approach to pregnancy care for women with disabilities may be offered within well-developed health systems [18].

There was no evidence of effect modification by the women's caste status. There have been long-standing and highly politicized concerns that major caste-dependent differences remain, with lower maternal healthcare utilization among Dalits consistently reported in the literature [36-41]. Increases in public awareness and policy developments resulting from these concerns may have contributed to changes in social equity and improvements in utilization across caste groups, so it is possible that differences in service utilization resulting from caste-based factors [27] could have improved in response to activism and policy attention to this disparity.

Another finding that should generate additional research in the future is the fact that disabled women from non-Dalit households were less likely to get care than either disabled women from Dalit households or non-disabled, non-Dalit women. Our sample size is admittedly small, but this finding raises the question of what is going on with these disabled women. They are members of households that presumably have more access to resources, including funds for education, healthcare, and transportation that should allow them equal access to maternal healthcare as their non-disabled non-Dalit peers. However, that presumes that household resources are shared equally, and we know that people with disabilities sometimes are not allowed equal access within households. Rising expectations in more prosperous non-Dalit households may also make the presence of disabled women and their call on household resources more rather than less problematic.

The study identified a number of individual, socio-demographic, and family-related factors associated with maternal healthcare service utilization by women with disabilities. Parity was associated with increased likelihood of health facility delivery if it was a first 
birth, corresponding with previous studies in Nepal [42,43]. First-time mothers may perceive more risks due to a lack of prior childbirth experience or may have other anxieties stemming from a lack of reliable information.

Women's level of education and their knowledge and awareness were also strong predictors for utilization of services, with better educated women more likely to give birth at a HF and to receive PNC services, consistent with other's findings [44-47]. Educated women may have a greater understanding of the benefits of using services, as well as the autonomy and confidence to use them. Education may also increase women's status in their family, enabling greater self-determination to choose and access services more easily [48]. Disabled women, both Dalit and non-Dalit, consistently had less education than their non-disabled peers, and this may be an important explanatory factor for why disabled women utilized services less.

The samples available for analysis in this study were small for the complexity of the phenomena. This means that whilst directional, the findings should be treated with caution. However, they indicate that further studies with larger samples and more in-depth qualitative analysis would be justified.

\section{Limitations of the Study}

We acknowledge several constraints and limitations. This research was a part of a Safe Motherhood Project in southern Nepal; therefore, the study population was limited to the project district. Secondly, having a very specific 'hard to reach' population for the study, with narrow inclusion criteria (i.e., Dalit and women with disability having had at least one pregnancy between 2009 and 2014), limited the sample size. Furthermore, the small and disproportionate sample size had implications for data analysis, forcing the researchers to employ a logical collapse of the variables where possible to measure associations with other variables or outcomes. In several circumstances, the tests for association were calculated with a small figure, which may have implications for accuracy. Given the large number of comparisons made in the quantitative section, significant associations close to the 0.05 level should be interpreted with caution, as 1 in 20 tests may have a $p$-value below 0.05 purely due to chance [49]. However, consistent relationships were seen between disability status and some maternal healthcare outcomes, suggesting that at least for disability status, findings are robust.

Language and communication barriers were another prominent constraint in the study. They was mostly overcome by recruiting local research assistants and using a questionnaire translated into the local languages (Nepali and Bhojpuri). However, the need to exclude women with the most severe communication disabilities limits the capturing of the experiences of these women.

An additional limitation is that for the purposes of this study, we used the broad definition of 'disability' from the United Nations Convention on the Rights of Persons with Disabilities [12]. However, there are a range of factors related to the type and severity of disability that may lead to varying access to and experiences with the health services. More detailed studies in future are needed to better understand these variables between groups of disabled women.

\section{Conclusions}

The results of this study suggest that the disability status of pregnant Nepali women is a more powerful factor in limiting the utilization of health facility delivery and postnatal care than is caste. Associations between disability and maternal healthcare utilization outcomes appear to be explained by socio-demographic factors. Except for a weak effect modification by education in the utilization of four recommended ANC services by Dalits, there was no evidence of effect modification in the utilization of services by women's caste. The findings of this study suggest that more substantive quantitative and qualitative studies are warranted, and that policy and political discourse should be widened, to acknowledge and address the disparities and challenges faced by women with disabilities of all castes. 
Author Contributions: H.R.D. conceived and implemented the project. N.G. guided design and field implementation. M.K. provided input in study design, implementation, and writing. E.M. supported the statistical analysis, and the interpretation, and ensured the data analysis procedures. H.R.D. and A.C. prepared the manuscript, and N.G., M.K. and E.M. commented and provided their inputs for finalization. All authors have read and agreed to the published version of the manuscript.

Funding: Big Lottery Fund UK through Kidasha in Nepal funded the study. There was no role of the funding body in the study design, data collection, analysis, interpretation, or writing of the manuscript.

Institutional Review Board Statement: All subjects gave their informed consent for the participation in the study. The study was conducted in accordance with the Declaration of Helsinki, and the protocol was approved by the Nepal Health Research Council (NHRC)-Ref. no. 1184 and UCL ethics committee project ID: 5260/001. Additionally, approval was received from the government District Public Health Office in the study district. Verbal and signed consent was taken from all participants before conducting interviews. Parental consent was also obtained for participants under 16 years old.

Informed Consent Statement: Not Applicable.

Data Availability Statement: The datasets used and/or analyzed during the current study are available from the corresponding author on reasonable request.

Acknowledgments: The authors acknowledge the support and contribution of Kidasha and the colleagues-Janice Miller, Shanti Shirish, Ishwar Mainali, and Tanka Shrestha, for the implementation of this study; field work; and data analysis. In addition, the authors wish to acknowledge the support provided by Disabled People's Organizations (DPOs) and the local partner, NAMUNA, and its staff in Rupandehi. The authors are grateful to the women who shared their views and personal experiences.

Conflicts of Interest: The authors declare no conflict of interest.

$\begin{array}{ll}\text { Abbreviations } \\ \text { ANC } & \text { Antenatal Care } \\ \text { BLF } & \text { Big Lottery Fund } \\ \text { CI } & \text { Confidence Interval } \\ \text { DPO } & \text { Disabled Person's Organization } \\ \text { HF } & \text { Health Facility } \\ \text { NDHS } & \text { Nepal Demographic Health Survey } \\ \text { NGO } & \text { Non-Governmental Organization } \\ \text { OR } & \text { Odds Ratio } \\ \text { PNC } & \text { Post-Natal Care } \\ \text { UN } & \text { United Nations. }\end{array}$

\section{References}

1. MoH/NewEra/ICF-International. Nepal Demographic and Health Survey 2016; Ministry of Health: Kathmandu, Nepal, 2017.

2. Thaddeus, S.; Maine, D. Too far to walk: Maternal mortality in context. Soc. Sci. Med. 1994, 38, 1091-1110. [CrossRef]

3. ARROW. MDG 5 in Asia: Progress, Gaps and Challenges 2000-2010; ARROW: London, UK, 2010; pp. 1-8.

4. Bennett, L.; Dahal, D.R.; Govindasamy, P. Caste, Ethnic and Regional Identity in Nepal: Further Analysis of the 2006 Nepal Demographic and Health Survey; Macro International Inc.: Calverton, MD, USA, 2008.

5. Kumar, P.; Gupta, A. Determinants of Inter and Intra caste Differences in Utilization of Maternal Health Care Services in India: Evidence from DLHS-3 Survey. Int. Res. J. Soc. Sci. 2015, 4, 27-36.

6. GoN/NPC/CBS. National Population and Housing Census 2011 (National Report); GoN/NPC/CBS: Calverton, MD, USA, 2012; Volume 1.

7. Gurung, H.; The Dalit Context. Occas Pap Sociol Anthropol. Available online: http://nepjol.info/index.php/OPSA/article/ view / 1133 (accessed on 20 June 2008).

8. Nohrlind, R. Caste-based Discrimination in South Asia: Situational Overview, Responses and Ways forward 2009. Available online: https://idsn.org/wp-content/uploads/user_folder/pdf/New_files/EU/EU_Study_Caste_Discrimination_merged_ April2010.pdf (accessed on 4 September 2014).

9. Morrison, J.; Basnet, M.; Budhathoki, B.; Adhikari, D.; Tumbahangphe, K.; Manandhar, D.; Costello, A.; Groce, N. Disabled women's maternal and newborn health care in rural Nepal: A qualitative study. Midwifery 2014, 30, 1132-1139. [CrossRef] [PubMed] 
10. Pandey, J.P.; Dhakal, M.R.; Karki, S.; Poudel, P.; Pradhan, M.S. Maternal and Child Health in Nepal: The Effects of Caste, Ethnicity, and Regional Identity: Further Analysis of the 2011 Nepal Demographic and Health Survey; Nepal Ministry of Health and Population, New ERA, and ICF International: Calverton, MD, USA, 2013.

11. Saroha, E. Caste as a Determinant of Utilization of Maternal and Neonatal Healthcare Services in Maitha, Uttar Pradesh, India. Available online: https:// search.proquest.com/docview/304893270?pq-origsite=gscholar\&fromopenview=true (accessed on 1 July 2014).

12. United Nations. Convention on the Rights of Persons with Disabilities and Optional Protocol 2006. Available online: https: //www.un.org/disabilities/documents/convention/convoptprot-e.pdf (accessed on 5 February 2014).

13. WHO; The World Bank. World Report on Disability. 2011. Available online: https://www.who.int/disabilities/world_report/20 11/report.pdf (accessed on 8 February 2014).

14. Shrestha, E.; Nilsson, A. Mainstreaming disability in the new development paradigm: Evaluation of Norwegian support to promote the rights of persons with disabilities (Nepal country report). Nordic Consult. Group 2012, 1, 215.

15. Anon. Maternal and new-born care practices among disabled women, and their attendance in community groups in rural Makwanpur, Nepal. London; 2013. (Background Paper: 01). Available online: https://www.gov.uk/research-for-developmentoutputs / maternal-and-new-born-care-practices-among-disabled-women-and-their-attendance-in-community-groups-inrural-makwanpur-nepal (accessed on 13 July 2013).

16. Becker, H.; Stuifbergen, A.; Tinkle, M. Reproductive health care experiences of women with physical disabilities: A qualitative study. Arch. Phys. Med. Rehabil. 1997, 78, S26-S33. [CrossRef]

17. Lipson, J.G.; Rogers, J.G. Pregnancy, birth, and disability: Women's health care experiences. Health Care Women Int. 2000, 21, 11-26. [PubMed]

18. Redshaw, M.; Malouf, R.; Gao, H.; Gray, R. Women with disability: The experience of maternity care during pregnancy, labour and birth and the postnatal period. BMC Pregnancy Childbirth 2013, 13, 174. [CrossRef] [PubMed]

19. Smith, E.; Murray, S.F.; Yousafzai, A.K.; Kasonka, L. Barriers to accessing safe motherhood and reproductive health services: The situation of women with disabilities in Lusaka, Zambia. Disabil. Rehabil. 2004, 26, 121-127. [CrossRef] [PubMed]

20. Trani, J.-F.; Browne, J.; Kett, M.; Bah, O.; Morlai, T.; Bailey, N.; Groce, N. Access to health care, reproductive health and disability: A large scale survey in Sierra Leone. Soc. Sci. Med. 2011, 73, 1477-1489. [CrossRef]

21. Dhungana, B.M. The lives of disabled women in Nepal: Vulnerability without support. Disabil. Soc. 2006, 21, 133-146. [CrossRef]

22. Khanal, N.A. Status of Reproductive Health and Experience of Motherhood of Disabled Women in Nepal. Midwifery 2014, 30, 1132-1139.

23. Saroha, E.; Altarac, M.; Sibley, L.M. Caste and Maternal Health Care Service Use Among Rural Hindu Women in Maitha, Uttar Pradesh, India. J. Midwifery Women's Health 2008, 53, e41-e47. [CrossRef]

24. Saxena, D.; Vangani, R.; Mavalankar, D.; Thomsen, S. Inequity in maternal health care service utilization in Gujarat: Analyses of district-level health survey data. Glob. Health Action 2013, 6, 1-9. [CrossRef]

25. Devkota, H.R.; Clarke, A.; Murray, E.; Groce, N. Do experiences and perceptions about quality of care differ among social groups in Nepal? A study of maternal healthcare experiences of women with and without disabilities, and Dalit and non-Dalit women. PLoS ONE 2017, 12, e0188554. [CrossRef]

26. MoHP/NewEra/ICF. International Inc. Nepal Demographic and Health Survey 2011; MoHP/NewEra/ICF: Kathmandu, Nepal, 2012.

27. Niraula, B.B. Use of health services in Hill villages in central Nepal. Health Transit. Rev. Cult. Soc. Behav. Determ. Health 1994, 4 , 151-166.

28. Davis, K. Intersectionality as buzzword: A sociology of science perspective on what makes a feminist theory successful. SAGE Publ. 2008, 9, 67-85. [CrossRef]

29. Buettgen, A.; Gorman, R.; Marcia Rioux KDas Vinayan, S. Employment, Poverty, Disability and Gender: A Rights Approach for Women with Disabilities in India, Nepal and Bangladesh. Women Ment. Health Resist Resil. Commun. Soc. 2015, 3-18. [CrossRef]

30. Bennett, L.; UNEQUAL CITIZENS: Gender, Caste and Ethnic Exclusion in Nepal. The World Bank and the Department for International Development, U.K. Available online: https://documents1.worldbank.org/curated/en/201971468061735968/pdf/ 379660Nepal0GSEA0Summary0Report01PUBLIC1.pdf (accessed on 12 October 2015).

31. DPHO. Annual Report 2069/70: District Public Health Office. Dep. Health Serv. 2014, 2069, 70.

32. Devkota, H.R. Maternal Health Care Service Access to Disabled and Dalit Women in Nepal; University College London (UCL): London, UK, 2017.

33. GoN/MoHP/FHD. National Medical Standard for Reproductive Health; Maternal and Neonatal Care: Kathmandu, Nepal, 2009; Volume III.

34. Malhotra, A.; Schuler, S.R.; Boender, C. Women's empowerment as a variable in International Development. In Background Paper Prepared for the World Bank Workshop on Poverty and Gender: New Perspectives; The World Bank: Washington, DC, USA, 2002; pp. 71-88.

35. Narayan, D. Measuring Empowerment: Conceptual Framework and Methodological Challenges; The World Bank: Washington, DC, USA, 2005; pp. 3-38.

36. GoN/MoHP/DoHS. Annual Report 2069/70 (2012/2013); GoN/MoHP/DoHS: Kathmandu, Nepal, 2013 ; Volume 70.

37. GoN/MoHP/PD. Nepal Population Report 2011; GoN/MoHP/PD: Kathmandu, Nepal, 2011. 
38. Khanal, V.; Adhikari, M.; Karkee, R.; Gavidia, T. Factors associated with the utilisation of postnatal care services among the mothers of Nepal: Analysis of Nepal Demographic and Health Survey 2011. BMC Women's Health 2014, 14, 19. [CrossRef] [PubMed]

39. MoHP/NewEra/OrgMacro. Nepal Demographic and Health Survey 2006. Available online: https://www.mohp.gov.np/eng/ publications /nepal-demographic-health-survey (accessed on 20 November 2007).

40. Paudel, D.R.; Pitakmanaket, O. Utilization of Maternal Health Services in Nepal. JHAS 2010, 1, 28-37. [CrossRef]

41. Shah, R.; Rehfuess, E.A.; Maskey, M.K.; Fischer, R.; Bhandari, P.B.; Delius, M. Factors affecting institutional delivery in rural Chitwan district of Nepal: A community-based cross-sectional study. BMC Pregnancy Childbirth 2015, 15, 27. [CrossRef] [PubMed]

42. Wagle, R.R.; Sabroe, S.; Nielsen, B.B. Socioeconomic and physical distance to the maternity hospital as predictors for place of delivery: An observation study from Nepal. BMC Pregnancy Childbirth 2004, 4, 8. [CrossRef] [PubMed]

43. Karkee, R.; Lee, A.H.; Pokharel, P.K. Women's perception of quality of maternity services: A longitudinal survey in Nepal. BMC Pregnancy Childbirth 2014, 14, 45. [CrossRef] [PubMed]

44. Ahmed, S.; Creanga, A.A.; Gillespie, D.G.; Tsui, A.O. Economic Status, Education and Empowerment: Implications for Maternal Health Service Utilization in Developing Countries. PLoS ONE 2010, 5, e11190. [CrossRef]

45. Celik, Y.; Hotchkiss, D.R. The socio-economic determinants of maternal health care utilization in Turkey. Soc. Sci. Med. 2000, 50, 1797-1806. [CrossRef]

46. Pandey, S.; Lama, G.; Lee, H. Effect of women's empowerment on their utilization of health services: A case of Nepal. Int. Soc. Work. 2011, 55, 554-573. [CrossRef]

47. Worku, A.G.; Yalew, A.W.; Afework, M.F. Factors affecting utilization of skilled maternal care in Northwest Ethiopia: A multilevel analysis. BMC Int. Heal. Hum. Rights 2013, 13, 20. [CrossRef]

48. Matsumura, M.; Gubhaju, B.B. Women's status, household structure and the utilization of maternal health services in Nepal. Asia-Pacific Popul. J. 2001, 16, 23-44. [CrossRef]

49. Dahiru, T. $p$-Value, A True Test of Statistical Significance? A Cautionary note. Ann. Ibadan. Postgrad. Med. 2008, 6, 21-26. [CrossRef] 